
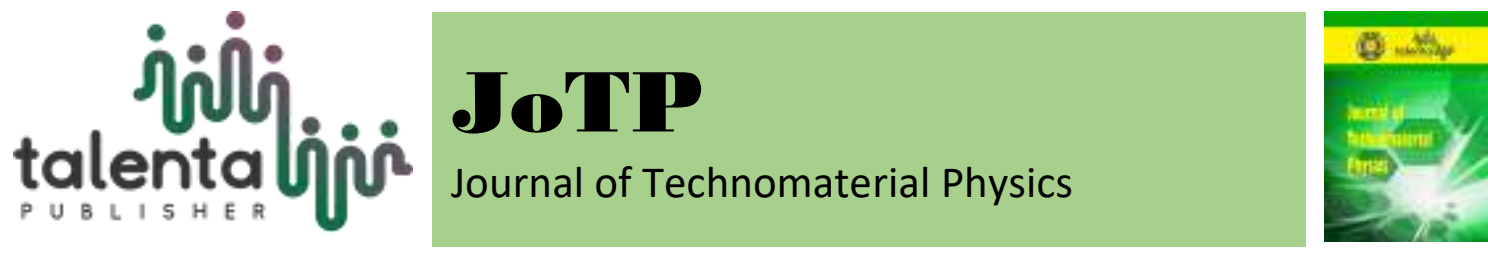

\title{
Effect of Thiourea as a Doping for Nanotitania
}

\author{
Nabilah Rafidiyah ${ }^{1}$, Posman Manurung ${ }^{2}$ and Pulung Karo Karo ${ }^{3}$ \\ ${ }^{1,2,3}$ Department of Physics, Faculty of Mathematics and Natural Science, University of Lampung 35145, \\ Indonesi
}

\begin{abstract}
Sulphur-doped $\mathrm{TiO}_{2}$ samples were prepared by sol gel method using thiourea as sulphur source. The amount of thiourea solutions are $0 ; 0.5 ; 1.0 ; 1.5$ and $2 \mathrm{ml}$, respectively. Sulphur-doped $\mathrm{TiO}_{2}$ was calcinated at $450^{\circ} \mathrm{C}$. Sulphur-doped $\mathrm{TiO}_{2}$ and pure $\mathrm{TiO}_{2}$ were characterized by X-Ray Diffraction (XRD), Transmission Electron Microscopy (TEM). Photo catalyst tests were carried out under sunlight and UV lamp. Based on XRD characterization, the samples are anatase phase. Furthermore, particle size was calculated using Scherrer equation and results of 8.94 and $12.98 \mathrm{~nm}$, respectively for TBT-1.5 and TBT-0.5. TEM characterization showed that particle size of sulphur-doped $\mathrm{TiO}_{2}$ and pure $\mathrm{TiO}_{2}$ are 8.6 and $12.5 \mathrm{~nm}$. Compared to $\mathrm{TiO}_{2}$ without doping, sulphur-doped $\mathrm{TiO}_{2}$ has a better photo catalyst activity for degradation of remazol golden yellow under visible light.
\end{abstract}

Keyword: $\mathrm{TiO}_{2}$, sulphur-doped, thiourea, photo catalyst, sol gel

Received 12 April 2019 | Revised [23 july 2019] | Accepted [31 August 2019]

\section{Introduction}

Nanotechnology is a technique to manipulate atoms, molecules or elements to produce materials and equipment with new properties. The role of nanotechnology is important for the revolution of science and engineering materials to obtain new materials with excellent electrical, optical, magnetic and mechanical properties. The magnitude of nanotechnology's role is illustrated by its broad scope, such as nanochemistry (nanocolloid, solum and quantum chemistry), nanophysics (quantum and photonic physics), nanomaterial science (nano powder technology, nano ceramic elements, and nanosintering), nanoelectronics (nanomotor, nanorobot and integrated circuits), nanobionic (nanobiochips and nanobiorobots) and nanometrology (nanoscale equipment, instrumentation and information systems) [1-3].

One of the rapidly expanding field of nanotechnology is nanomaterial. Nanomaterials have several types, namely nano steel, nanopowder, nanoceramics and nanopolymers [4]. Nanomaterials that have been widely produced in the market are nanosilica, nanotitania, nanoaluminia, fullerenes and carbon-based nanotubes (CNTs) [5].

\footnotetext{
*Corresponding author at: FMIPA University of Lampung, Bandar Lampung 35145, Indonesia

E-mail address: reip65@yahoo.com
} 
Among the various types of nanomaterials, titanium dioxide $\left(\mathrm{TiO}_{2}\right)$ or nanotitania is one of the ingredients being developed. Nanotitania has been widely applied in various fields as water purification, solar cells [6], anti-bacterial [7], the most widely used as photocatalysts [8]. Titanium dioxide has three polymorphous forms, namely rutile, anatase and brookite. The thermodynamically rutile phase is more stable than anatase phase, the rutile structure appears to be thermodynamically stable under pelletizing conditions, although in thermodynamic experiments it shows that anatase can be more stable than rutile when the crystal size is only a few nanometres. The anatase phase is a metastable form; and when treated with heat, it can be transformed into rutile. At room pressure and temperature for macrocrystalline systems, the thermodynamic rutile phase is more stable when compared to anatase and brookite. However, thermodynamic stability depends on particle size which contributes to surface free energy [9]. As a photocatalyst material, nanotitania is widely used because it is cheap, stable and non-toxic. Currently, nanotitania photocatalysts have been used for air cleaning, water purification, antitumour, self-cleaning materials [10], color-sensitive sun cells or Dye-sensitized Solar Cells (DSSC) [11], white dyes [12] and anti-blur [13].

Usage of nanotitania during the anatase phase, especially as a photocatalyst, only about $4 \%$ of sunlight can be used. This happens due to anatase's energy gap is $3.2 \mathrm{eV}$ [14]. In order to make the best use of nanotitania, various methods can be used to reduce bandgap, one of which is doping. Doping is a process to modify the conductivity of a material. There are various types of dopants in nanotechnology and semiconductors including $\mathrm{N}$ [15], C [16], S [17] and F [18].

This study was carried out by doping nanotitania with sulphur. Sulphur is a non-metallic chemical element that has the symbol S and atomic number 16. Sulphur has been widely used as a dopant of nanotitania, such as in a study conducted by Wang et al [19] which used tetrabutyl titanate (98\%) as a precursor and alcohol material (99.7\%) as a solvent which produced nanotitania with a sulphur content of $1.21 \%$. It displayed better photo absorption properties compared to pure titania. In addition, the average size of nanotitania doped with sulphur is smaller, which is equal to $9.73 \mathrm{~nm}$ compared to pure nanotitania which measures at $17.36 \mathrm{~nm}$. Hence, it explains that nanotitania photocatalytic activity doped with sulphur for L-acid photodegradation is better than pure nanotitania. Therefore, this study was conducted to analyse the effect of thiourea as a source of sulphur doping for the synthesis of nanotitania with titanium butoxide as a base for nanotitania photo catalyst activity.

\section{Materials and Methods}

The making of nanotitania S-doping powder is done by synthesizing the results of mixing between butanol, titanium butoxide $97 \%, 37 \% \mathrm{HCl}$ and $99 \%$ thiourea with certain mixture using the sol-gel method. In this case, titanium butoxide acts as a precursor, butanol acts as a solvent and thiourea acts as a source of sulphur doping. 
The synthesis process was carried out by making two solutions, namely titania solution and thiourea solution. The thiourea solution contained $7.612 \mathrm{gr}$ of thiourea powder which is dissolved in $100 \mathrm{ml}$ of double-distilled water. The titanium dioxide solution contained $10 \mathrm{ml}$ of titanium butoxide which was dissolved drop by drop into $80 \mathrm{ml}$ of butanol which was then stirred using a magnetic stirrer for 30 minutes. Afterwards, $0.5 \mathrm{HCl} \mathrm{ml} \mathrm{was} \mathrm{added} \mathrm{and} \mathrm{was}$ stirred for 30 minutes. Thiourea solution was added with a composition of each sample of $0 ; 0.5 ; 1.0 ; 1.5$ and $2 \mathrm{ml}$. Table 1 shows variations in sample composition.

Table 1. Variation in sample composition.

\begin{tabular}{ccccc}
\hline Sample & $\begin{array}{c}\text { Titanium butoxide } \\
(\mathrm{ml})\end{array}$ & $\begin{array}{c}\text { Butanol } \\
(\mathrm{ml})\end{array}$ & $\begin{array}{c}\text { Thiourea } \\
(\mathrm{ml})\end{array}$ & $\begin{array}{c}\text { Mol comparison } \\
(\mathrm{TiO} 2: \mathrm{S})\end{array}$ \\
\hline TBT-0 & 10 & 80 & 0.0 & - \\
TBT-0.5 & 10 & 80 & 0.5 & $1: 0.0178$ \\
TBT-1.0 & 10 & 80 & 1.5 & $1: 0.0357$ \\
TBT-1.5 & 10 & 80 & 1.5 & $1: 0.0536$ \\
TBT-2.0 & 10 & 80 & 2.5 & $1: 0.0714$ \\
\hline
\end{tabular}

The stirring was continued for 12 hours in order to spot the differences in the five samples. After the three ingredients were mixed, the materials was dried by using an oven at a temperature of $\sim 80^{\circ} \mathrm{C}$ for 24 hours. After that, calcination was carried out at $450^{\circ} \mathrm{C}$ for 10 hours. Then, the five samples were crushed using agate mortar to fine nanotitania powder and $\mathrm{XRD}$ and TEM were carried out as well as photocatalyst test using $10 \mathrm{ppm}$ remazol golden yellow as the pollutant.

\section{Result and Discussion}

\subsection{XRD Analysis}

Figure 1 shows the XRD results from TBT- 0 and TBT- 1.5 samples. The XRD pattern of TBT- 0 and TBT-1.5 samples shows that the phase formed is the anatase phase. Three highest peaks are identified at the diffraction angle of $25.26^{\circ} ; 37.78^{\circ}$ and $48.16^{\circ}$ with hkl positions as follows (101), (004) and (200) for the TBT-0 sample. Whereas for the TBT-1.5 sample there are three highest peaks at the diffraction angle of $25.39^{\circ} ; 37.72^{\circ}$ and $53.81^{\circ}$ with hkl positions as follows (101), (004) and (200).

The XRD pattern of TBT-0 and TBT-1.5 samples shows that the phase formed is the anatase phase. This is also supported by matching the results of XRD pattern analysis using standard JCPDS 21-1272 data using PCPDFWIN version 1.3 JCPDS-ICDD 1997 software. The average particle size calculated using the Scherrer equation for TBT-0 or pure $\mathrm{TiO}_{2}$ samples is $12.98 \mathrm{~nm}$ and a sample of TBT-1.5 or S-doping nanotitania is $8.94 \mathrm{~nm}$. 


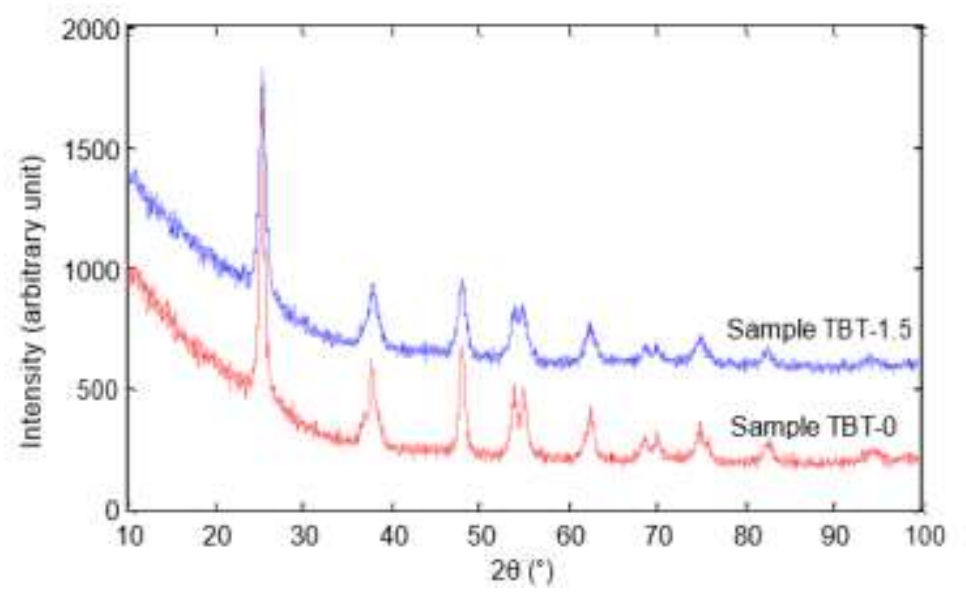

Figure 1. XRD results of TBT-0 and TBT-1.5 samples. X-ray wavelength

$$
\lambda=1.54056 \AA \text {. }
$$

In order to figure out the value of cell parameters, cell angle and preferred orientation, quantitative analysis was carried out using the Rietveld method. The softener used for smoothing is Rietica. The crystal data used as input is the model used by Djerdj et al [20]. The plot to refine the TBT-0 sample is displayed in Figure 2. The pattern shows that refining the XRD diffractogram of the TBT-0 sample is sufficient. This can be seen based on the difference between the observation data and the calculation results is relatively small, which is 1.052. From this smoothing process, it was found that the TBT-0 sample possessed anatase behavior with cell parameters $(\mathrm{a}=\mathrm{b}=3.7841 \AA$ and $\mathrm{c}=9.5072 \AA)$, the cell angle $\left(\alpha=\beta=\gamma=90^{\circ}\right)$, the cell volume was 136,14 , the number of formulas per unit cell $(\mathrm{Z})$ is 4 and the positions of Ti and $\mathrm{O}(\mathrm{x}=0, \mathrm{y}=0.25, \mathrm{z}(\mathrm{Ti})=0.375$ and $\mathrm{z}(\mathrm{O})=0.168)$. These values approach the refining parameters carried out by Djerdj et al [20].

XRD analysis data from TBT-1.5 samples were also analyzed using the Rietveld method and the crystal data used was the model. The output plot of the TBT-1.5 refining sample is shown in Figure 3. The pattern shows that the XRD diffractogram of the TBT-1.5 sample is sufficient. This can be seen based on the difference between the observation data and the calculation results are relatively small, which is 1.066 . From this smoothing process, it was found that the TBT-1.5 sample had an anatase phase with cell parameters $(\mathrm{a}=\mathrm{b}=3.7904 \AA$ and $\mathrm{c}=9.4938 \AA$ ), the cell angle $\left(\alpha=\beta=\gamma=90^{\circ}\right)$, and cell volume $136.40 \AA 3$. These values were close to the refining parameters value carried out by Djerdj et al [20].

XRD analysis data from TBT-1.5 samples were also analyzed using the Rietveld method and the crystal data used was the Djerdj [20] model. The output plot of the TBT-1.5 refining sample is shown in Figure 3. The pattern shows that the XRD diffractogram of the TBT-1.5 sample is sufficient. This can be seen based on the difference between the observation data and the calculation results are relatively small, which is 1.066 . From this smoothing process, it was found that the TBT-1.5 sample had an anatase phase with cell parameters $(\mathrm{a}=\mathrm{b}=3.7904 \AA$ and 
$\mathrm{c}=9.4938 \AA)$, the cell angle $\left(\alpha=\beta=\gamma=90^{\circ}\right)$, and cell volume $136.40 \AA 3$. These values were close to the refining parameters value carried out by Djerdj et al [20].

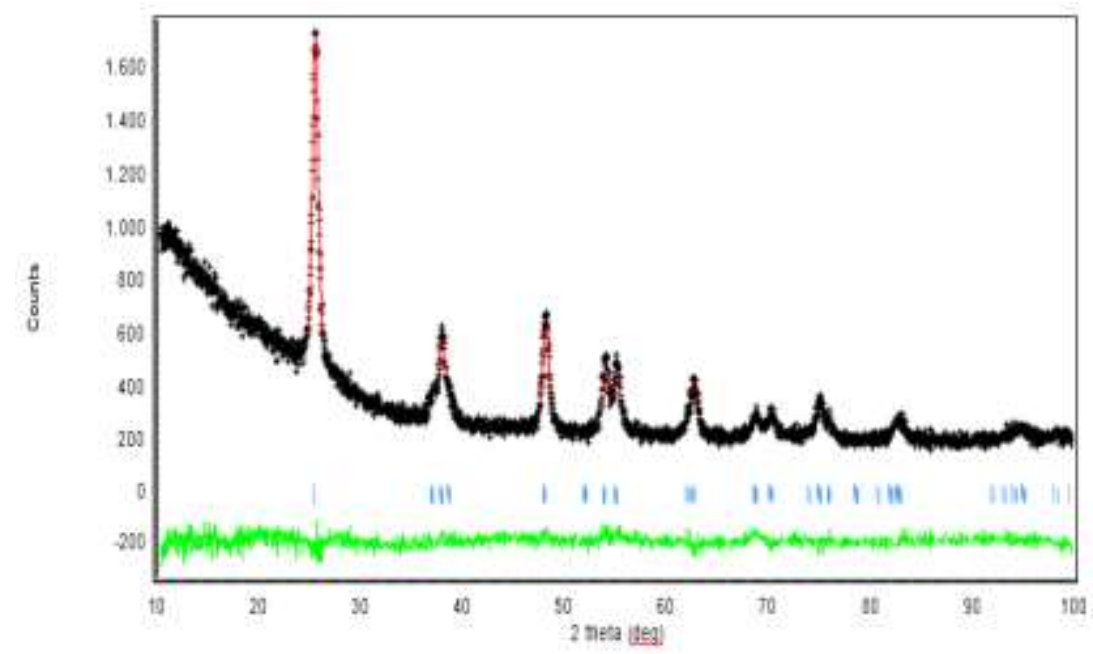

Figure 2. Plot of TBT-0 sample smoothing output. The black color displays the observation data, the red color displays the result from the calculation, the green color displays the difference between the observation data and the calculation results and the blue color displays the peak point of the hkl.

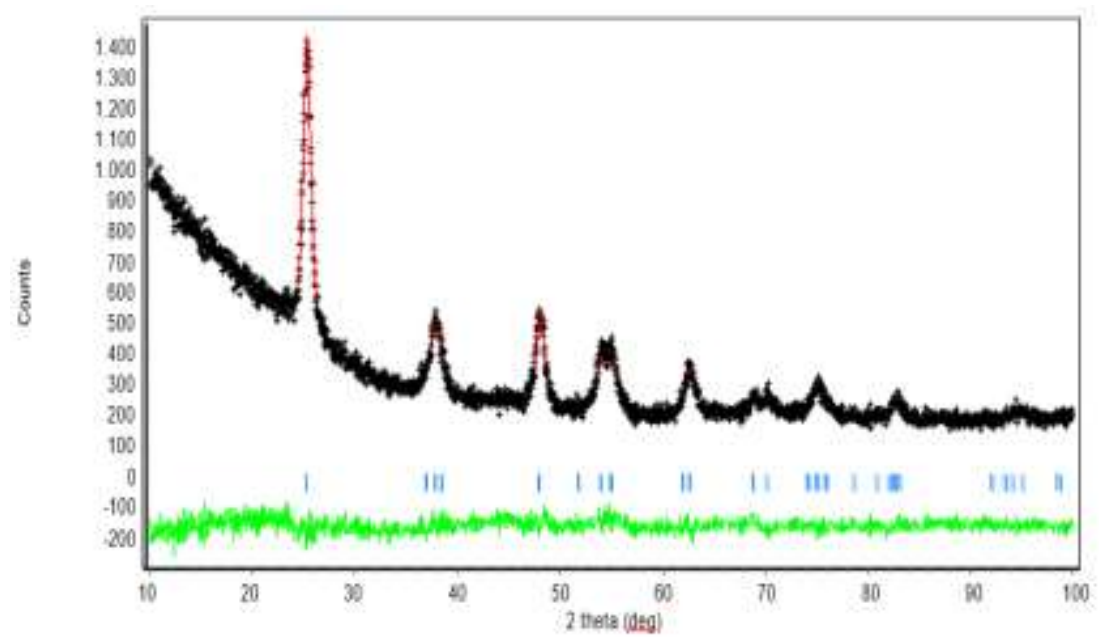

Figure 3. Plot of TBT-1.5 sample smoothing output. The black color displays the observation data, the red color displays data from the calculation, the green color displays difference between the observation data and the calculation displays and the color shows the peak point of the hkl.

\subsection{TEM Analysis}

Figure 4 shows the photographic results of TEM samples of TBT- 0 or pure $\mathrm{TiO}_{2}$ (Figure $4 \mathrm{a}$ ) and TBT-1.5 or S-doping $\mathrm{TiO}_{2}$ (Figure $4 \mathrm{~b}$ ). The average particle size of pure $\mathrm{TiO}_{2}$ is $12.5 \mathrm{~nm}$ and the average particle size of $\mathrm{S}$-doping $\mathrm{TiO}_{2}$ is $8.6 \mathrm{~nm}$. In addition, nanoparticle adhesion occurred in the TBT-1.5 sample. This adhesion of nanoparticles results in increased number of pores and decreased particle size. 

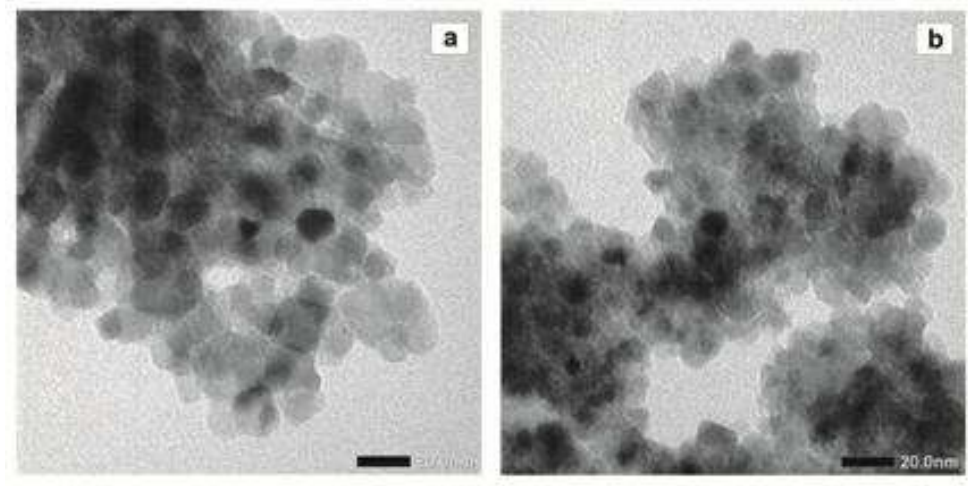

Figure 4. TEM images: (a) TBT-0 and (b) TBT-1.5

Based on the calculation of particle size using XRD analysis data and the results of particle size measurements using TEM photo results, particle size for both TBT-0 and TBT-1.5 samples has consistent results. Thus, both samples can be confirmed as nanomaterials.

\subsection{Photocatalyst Test}

Figure 5 shows the photocatalyst test of all samples under the sun and UV lights. From Figure 5 it can be seen that the absorbance value decreases with the length of irradiation time for all samples both under ultraviolet and sunlight. However, samples with $\mathrm{S}$ doping give much greater photodegradation results than pure nanotitania (sample TBT-0). This indicates that the presence of S doping on nanotitania can increase nanotitania activity for photocatalyst applications. The best photocatalytic activity under UV lamps and sunlight respectively were TBT-1.5 and TBT0.5 samples. This can be seen from the absorbance values of TBT-1.5 and TBT- 0.5 at the time of irradiation of 50 minutes, namely 0.111 and 0.173 . The low absorbance value also indicates that the concentration of remazol golden yellow solution is reduced due to the high photocatalyst activity of TBT-1.5 and TBT-0.5, where both samples are S-doping $\mathrm{TiO}_{2}$. Thus, it can be concluded that the $\mathrm{S}$-doping $\mathrm{TiO}_{2}$ photocatalyst activity is better than pure $\mathrm{TiO}_{2}$. 

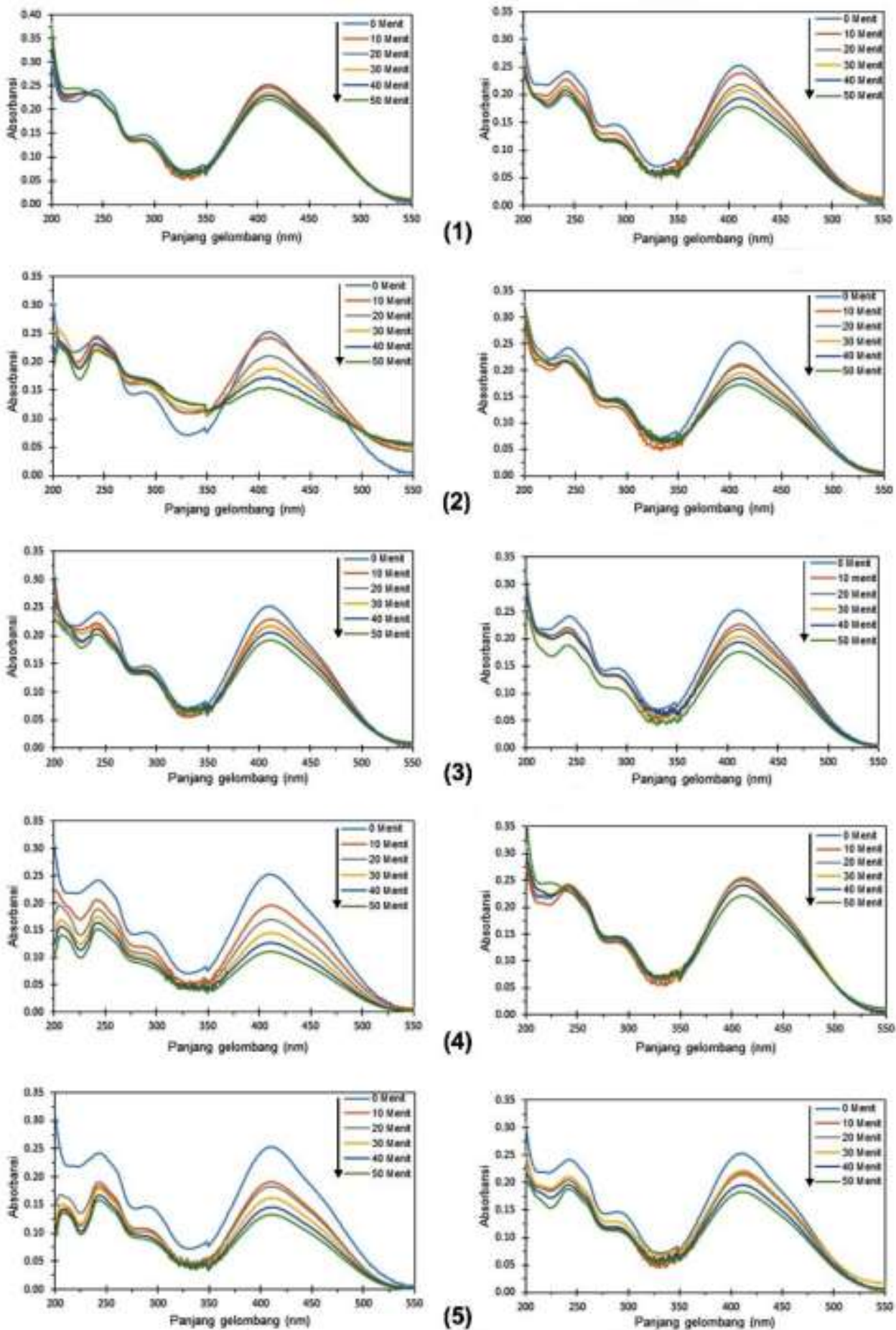

(a)

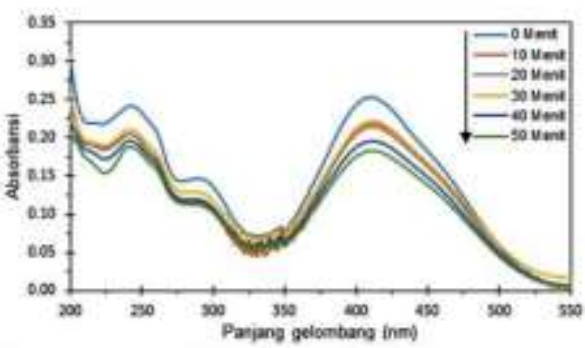

(b)

Figure 5. Results of UV-Vis spectrophotometry review: (1) TBT-0; (2) TBT-0.5; (3) TBT-1.0; (4) TBT-1.5 and (5) TBT-2.0 against absorbance (a) under UV lights and (b) under sunlight.

\section{Conclusion}

The S-doping phase of $\mathrm{TiO}_{2}$ and $\mathrm{TiO}_{2}$ which was prepared through the sol gel method and calcinated at $450^{\circ} \mathrm{C}$ is the anatase phase. The particle size of pure $\mathrm{TiO}_{2}$ and $\mathrm{S}$-doping $\mathrm{TiO}_{2}$ through calculations from the XRD results were 12.98 and $9.8 \mathrm{~nm}$ respectively. While the particle size of $\mathrm{TiO}_{2}$ and S-doping $\mathrm{TiO}_{2}$ through measurements from TEM photo results were 
Journal of Technomaterial Physics Vol. 1, No. 2, 2019 / $83-91$

12.5 and $8.6 \mathrm{~nm}$ respectively. Both analyzes, namely XRD and the results of measurements with TEM photo results provide consistent results. Maximum photocatalyst activity occurs in TBT1.5 samples when irradiated under UV lamps and in TBT-0.5 samples when illuminated in the sun.

\section{Acknowledgement}

The author would like to thank Padang State University for the XRD test, Gadjah Mada University for the TEM test and Analytical Chemistry Laboratory of the Faculty of Mathematics and Natural Sciences, University of Lampung for UV-Vis spectrophotometry.

\section{References}

[1] V. Pokropivny, I. Hussainnova, S. Vlassor, A. Pokropivny and R. Lohmus, Introduction To Nanomaterials and Nanotechnology, Tartu: Tartu University Press, 2007.

[2] M. S. Mauter, I. Zucker, F. Perreault, J. R. Werber, J-H. Kim and M. Elimelech, "The Role of Nanotechnology in Tackling Global Water Challenges," Nature Sustainability, vol. 1, no. 4, pp. 166-175, 2018.

[3] J. Lu, Z. Chen, Z. Ma, F. Pan, L. A. Curtiss and K. Amine, "The Role of Nanotechnology In The Development of Battery Materials for Electric Vehicles," Nature nanotechnology, vol. 11, no. 12, pp. 1031-1038, 2016.

[4] J. Morris and J. Willis, Environmental Protection Agency, Washington: United States Environmental Protection Agency, 2005.

[5] C. Lauterwasser, Opportunities and Risks of Nanotechnologies, Munchen: Allianz AC, 2006.

[6] Y. F. You, C. H. Xu, S. S. Xu, S. Cao, J. P. Wang, Y. B. Huang and S. Q. Shi, "Structural Characterization and Optical Property of $\mathrm{TiO}_{2}$ Powders Prepared by The Sol-Gel Method," Ceramics International, vol. 40, no. 6, pp. 8659-8666, 2014.

[7] M-S. Wong, D-S. Sun and H-H. Chang, "Bactericidal Performance of Visible-Light Responsive Titania Photocatalyst with Silver Nanostructures," Journal of Plos One, vol. 5, no. 4, e10394, 2010.

[8] K. Nakata and A. Fujishima, "TiO $\mathrm{TiO}_{2}$ Photocatalysis: Design and Applications," Journal of Photochemistry and Photobiology C: Photochemistry Reviews, vol. 13, no. 3, pp. 169-189, 2012.

[9] E. A. D. Kiswanti and S. Pratapa, "Sintesis Titanium Dioksida $\left(\mathrm{TiO}_{2}\right)$ Menggunakan Metode Logam-Terlarut Asam," Jurnal Sains dan Seni Pomits, vol. 3, no. 2, pp. B18-B21, 2013.

[10] A. Fujishima, T. N. Rao and D. A. Tryk, "Titanium Dioxide Photocatalysis," Journal of Photochemistry and Photobiology C: Photochemistry Reviews,, vol. 1, no. 1, pp. 1-21, 2000.

[11] J. Huberty and H. Xu, "Kinetics Study on Phase Transformation from Titania Polymorph Brookite to Rutile," Journal of Solid State Chemistry, vol. 181, no. 3, pp. 508-514, 2008.

[12] K. Hashimoto, H. Irie and A. Fujishima, " $\mathrm{TiO}_{2}$ Photocatalysis: A Historical Overview and Future Prospects," Japanese Journal of Applied Physics, vol. 44, no. 12, pp. 8269-8285, 2005.

[13] S. Sinha, N. G. T. Orozco, D. S. A. Ramirez and R. Rodriguez-Vazquez, "Effect of Surfactant on $\mathrm{TiO}_{2} / \mathrm{UV}$ Mediated Heterogeneous Photocatalytic Degradation of DDT in Contaminated Water," TechConnect Briefs, vol. 2, pp. 411-414, 2009.

[14] N. N. Binitha, Z. Yaakob and R. Resmi, "Influence of Synthesis Methods on Zirconium Doped Titania Photocatalysts," Central European Journal of Chemistry, vol. 8, no. 1, pp. $182-187,2010$. 
Journal of Technomaterial Physics Vol. 1, No. 2, 2019 / 83 - 91

[15] X. F. Lei, X. X. Xue, H. Yang, C. Chen, X. Li, M. C. Niu, X. Y. Gao and Y. T. Yang, "Effect of Calcination Temperature on the Structure and Visible-light Photocatalytic Activities of (N, S and C) Co-doped $\mathrm{TiO}_{2}$ Nano-materials," Applied Surface Science, vol. 332, pp. 172-180, 2015.

[16] L. Mai, C. Huang, D. Wang, Z. Zhang and Y. Wang, "Effect of C Doping on The Structural and Optical Properties of Sol - gel $\mathrm{TiO}_{2}$ Thin Films," Applied Surface Science, vol. 255, no. 22, pp. 9285-9289, 2009.

[17] T. Ohno, M. Akiyoshi, T. Umebayashi, K. Asai, T. Mitsui and M. Matsumura, "Preparation of S-doped $\mathrm{TiO}_{2}$ Photocatalysts and Their Photocatalytic Activities under Visible Light," Applied Catalysis A:General, vol. 265, no. 1, pp.115-121, 2004.

[18] E. Fakhrutdinova, A. V. Shabalina and E. Sudareva, "Synthesis of $\mathrm{TiO}_{2}$ and F-Doping $\mathrm{TiO}_{2}$ Powders Via 'Reverse' Hydrolysis of Titanium Tetraisopropoxide," Advanced Materials Research, vol. 1085, pp. 95-100, 2015.

[19] Y. Wang, J. Li, P. Peng, T. Lu and L. Wang, "Preparation of S-TiO2 Photocatalyst and Photodegradation of L-acid under Visible Light," Applied Surface Science, vol. 254, no. 16, pp. 5276-5280, 2008.

[20] I. Djerdj and A. M. Tonejc, "Structural Investigations of Nanocrystalline TiO2 Samples," Journal of Alloys and Compounds, vol. 413, no. 1-2, pp 159-174, 2006. 